\title{
Retomar a crítica interna do capitalismo? Revisitando a análise das crises em Problemas de legitimação no capitalismo tardio de Habermas*
}

\author{
Leonardo Jorge da Hora Pereira \\ Doutorando em Filosofia pela Universidade de Paris-Nanterre, França
}

Resumo: 0 trabalho de Jürgen Habermas se notabilizou por seus estudos sobre temas como a esfera pública, a ética do discurso e a ação comunicativa. No entanto, diante da atual crise do capitalismo, talvez seja produtivo revisitar um momento de sua experiência intelectual que foi, em certo sentido, relegado ao segundo plano. Trata-se dos teoremas de crise do capitalismo tardio elaborados em Problemas de legitimação no capitalismo tardio (1973). Tendo em vista que a teoria crítica parece estar hoje diante do desafio de trazer de volta para 0 centro de sua produção uma reflexão sobre os desequilíbrios e eventuais limites internos do capitalismo, argumentarei nesse artigo que 0 tipo de análise que Habermas empreende nesta obra pode nos oferecer elementos para a elaboração de diagnósticos do capitalismo contemporâneo.

Palavras-chave: Habermas; capitalismo; crises; teoria crítica
Abstract: The work of Jürgen Habermas became famous for his studies on topics such as public sphere, discourse ethics and communicative action. However, given the current crisis of capitalism, it may be productive to revisit a moment of his intellectual experience that was, in a sense, relegated to the background: the crisis theorems of late capitalism, discussed by him in Legitimation Crisis (1973). In this article, we argue that, at a time when critical theory seems to face the challenge of bringing back a reflection about the imbalances and the possible internal limits of capitalism, the kind of analysis that Habermas undertakes in this work can offer us elements for developing new diagnoses of contemporary capitalism.

Keywords: Habermas; capitalism; crisis; critical theory

Este artigo é uma adaptação do terceiro capítulo da minha dissertação de mestrado, defendida em setembro/2012 na Unicamp (Cf. DA HORA PEREIRA, L, A noção de capitalismo tardio na obra de Jürgen Habermas: em torno da tensão entre capitalismo e democracia. Campinas, 232p. Dissertação de mestrado 


\section{Introdução}

A crise financeira global iniciada em 2007 no centro do capitalismo nos relembrou da velha máxima marxiana, segundo a qual as crises são um elemento constitutivo do capitalismo². Como consequência, o fenômeno da crise no capitalismo começa a ser retomado enquanto um dos momentos privilegiados da crítica, para que esta não fique aquém do seu tempo presente ${ }^{3}$. Nesse sentido, um dos desafios

em filosofia. UNICAMP, 2012). Desse modo, agradeço à minha orientadora Yara Frateschi pelo incentivo e pela orientação desde a graduação. Agradeço também aos professores Marcos Nobre, Rúrion Soares Melo e Alessandro Pinzani, que compuseram as bancas de qualificação e/ou defesa e que muito contribuíram com suas valiosas sugestões. Evidentemente, as eventuais deficiências são de minha responsabilidade.

2. A literatura que vem se desenvolvendo no bojo desta crise é enorme. Destacaremos tão somente duas obras : STREECK, W. As crises do capitalismo democrático. In: Novos estudos - CEBRAP, São Paulo, n. 92, Mar. 2012; DUMENIL, G. \& LEVY, D. The Crisis of Neoliberalism. Cambridge, Massachussetts, London, England: Harvard University Press, 2011.

3. A teórica crítica norte-americana Nancy Fraser parece acompanhar tal intuição, quando afirma num texto de conferência que: "Hoje, no entanto, essas verdades se encontram em frangalhos. Com o sistema financeiro global vacilante, com a produção mundial e o emprego em queda livre, e a perspectiva iminente de uma recessão prolongada, o aspecto econômico da crise capitalista é impossível de ignorar. Mas o mesmo é verdade do aspecto ecológico, dado o aquecimento global, o agravamento da poluição, esgotamento de recursos, e novas formas de bio-mercantilização que penetram o real núcleo da natureza. Então, também, a dimensão social da crise é cada vez mais saliente - os bairros devastados, as famílias deslocadas e as comunidades devastadas pela guerra e pelas doenças que cruzam nosso planeta de favelas são testemunhas disso. Também não se pode ignorar a dimensão política: a crise, em primeiro lugar, do Estado territorial moderno, em segundo lugar, dos seus pretensos sucessores regionais, sobretudo da União Européia, em terceiro lugar, da hegemonia dos EUA, e quarta, das instituições globais de governança - falta a todos eles a imaginação para vislumbrar soluções e a vontade e capacidade de implementá-las. Finalmente, há a crise da própria crítica e a crise da emancipação, uma vez que nem os teóricos críticos, nem os movimentos sociais emancipatórios, até agora, demonstraram capacidade de lidar com essa situação. Uma crise deste tipo, multidimensional e sobredeterminada, fornece o cenário inevitável para toda tentativa séria de teorização crítica. Doravante, tal teorização não pode mais evitar a questão da sociedade capitalista. A teorização social em larga escala, com o objetivo 
da teoria social crítica hoje parece ser o de dar conta da ideia de que o capitalismo pode encontrar problemas ou limites internos sem incorrer nos antigos problemas do mecanicismo, do catastrofismo e das teorias do colapso "automático" do sistema, ou ainda sem recair em uma compreensão simplista, que reduz o capitalismo exclusivamente ao âmbito da produção ou da economia.

Acreditamos que este é um momento oportuno para revisitar uma obra de Habermas que ficou, de certa forma, em segundo plano na recepção de seu pensamento, assim como de avaliar até que ponto ela pode ainda contribuir para a compreensão da situação atual. Trata-se de Legitimationsprobleme im Spätkapitalismus (Problemas de legitimação no capitalismo tardio), livro publicado originalmente em 1973, onde Habermas se dedica a elaborar sistematicamente teoremas de crise para o capitalismo europeu de sua época, isto é, o capitalismo regulado pelo Estado de Bem-estar social. Diante da crise contemporânea, é exatamente esse projeto que nos interessa aqui.

Nos diferentes modelos críticos propostos por Habermas nas décadas de 1960 e 70, o problema central parece ser o mesmo: ainda que sob o capitalismo tardio a sociedade tenha se repolitizado, com o intervencionismo estatal, e se tornado compatível com uma democracia de massas, os cidadãos permanecem passivos e apolíticos ${ }^{4}$. Eles teriam se tornado meros clientes do Estado social, que desenvolveu um programa de substitutivos. Apesar das semelhanças, há diferenças importantes nas obras de Habermas desse período. No artigo programático de 1968, "Técnica e Ciência como Ideologia", o que aparece em primeiro plano é uma teoria da evolução social e da racionalização. Aqui, Habermas introduz um expediente de critica da razão que será

de esclarecer a natureza e as raízes da crise, bem como as perspectivas para uma resolução emancipatória, deve recuperar o seu lugar central na teoria crítica". (FRASER, N. Marketization, Social Protection, Emancipation: Toward a Neo-Polanyian Conception of Capitalist Crisis. Disponível em http://f.hypotheses.org/wp-content/blogs.dir/203/files/2012/02/TexteNancy-Fraser-anglais.doc. Acesso em 07/2012, pp. 1-2).

4. Este tipo de argumento, que faz referência à dicotomia entre uma sociedade repolitizada e uma massa de cidadãos despolitizada, pode ser encontrado, por exemplo, em HABERMAS, J. Student und Politik: Eine soziologische Untersuchung zum politischen Bewusstsein Frankfurter Studenten. Neuwied: Hermann Luchterhand Verlag, 1961, p. 24; bem como em HABERMAS, J. Technik und Wissenschaft als "Ideologie". Frankfurt: Suhrkamp, 1968, pp. 76-7. 
retomado e aprofundado mais adiante, em Teoria da Ação Comunicativa (1981). Em Problemas de legitimação no capitalismo tardio, por sua vez, Habermas retoma, com algumas ressalvas, o expediente marxista de uma teoria das crises do capitalismo ${ }^{5}$ e procura repensar o vínculo entre crítica e crise. Sem abandonar uma teoria da evolução social, da modernidade e da racionalização, o que aparece em primeiro plano agora é a ideia de que o capitalismo pode encontrar limites internos à sua expansão. Em outras palavras, em 1973, Habermas vincula a crítica à elaboração de teoremas de crises por meio de um modelo descritivo do capitalismo tardio, atualizando, em certo sentido, o procedimento marxista desenvolvido em O Capital ${ }^{6}$.

Contudo, partindo do diagnóstico de que a política não é mais um fenômeno superestrutural na dinâmica do capitalismo avançado, Habermas tenta apreender o capitalismo não apenas como um "modo de produção", mas como uma formação social complexa, passível de outros tipos de crises, além da propriamente econômica. Ao abordar o capitalismo de modo mais amplo, Habermas procura também identificar os pontos de tensão e limites que o capitalismo impõe à democracia.

Embora o capitalismo contemporâneo não seja mais aquele do qual Habermas fala em 1973, acreditamos que sua abordagem complexa sobre o capitalismo e suas crises pode ser bastante útil na elaboração de um novo diagnóstico de época. Tendo isso em vista, o presente artigo tem como objetivo apresentar alguns elementos desta abordagem, assim como dar algumas indicações de como este expediente poderia ser reatualizado hoje.

\section{O diagnóstico do capitalismo tardio}

Dado que o capitalismo da segunda metade do século XX não é mais aquele da época de Marx, para compreendermos o que Habermas entende por crise, é preciso primeiro analisar quais os tipos de transformação que marcam a passagem do capitalismo liberal ou concorrencial para o capitalismo tardio ou organizado.

5. Cf. BENHABIB, S., Critique, Norm and Utopia. New York: Columbia University Press, 1986, p. 229.

6. Cf. MCCARTHY, T. The Critical Theory of Jürgen Habermas. Cambridge: MIT Press, 1981, p. 358. 
Segundo Habermas, a expressão "capitalismo organizado" (organisierter Kapitalismus) ou "regulado pelo Estado" (staatlich geregelter) diz respeito a duas classes de fenômenos: de um lado, o processo de concentração das empresas (a aparição das corporações, das sociedades nacionais e multinacionais) e a organização dos mercados de trabalho, de capitais e de bens; de outro lado, o fato de que o Estado intervencionista se imiscui nas lacunas funcionais do mercado ${ }^{7}$. No campo econômico, desenvolve-se um setor privado que é determinado pelas estratégias do mercado de oligopólio - é o setor monopolista, que possui grande capacidade de expandir continuamente as forças produtivas por meio da racionalização dos salários, dos preços, dos lucros, do consumo e da inovação técnica ${ }^{8}$. Isso traz, contudo, uma importante consequência. Enquanto as análises de Marx da queda tendencial da taxa de lucro pressupunham um capitalismo concorrencial e anárquico, a produção monopolista tende a complicar essa equação A determinação dos preços da mão-de-obra, por exemplo, passam a ser negociados junto à burocracia por oligopólios e pelos sindicatos e não são mais determinados por mecanismos mercadológicos, abrindo assim a possibilidade para um compromisso de classe. No setor público, grandes empresas tomam decisões de modo largamente independente do mercado.

No âmbito estatal, há também novos elementos responsáveis pelo questionamento dos prognósticos de crise da análise marxista. $\mathrm{O}$ aparelho de Estado passa a satisfazer dois tipos de imperativos econômicos. De um lado, ele regula o ciclo econômico, graças à planificação global. De outro lado, ele melhora as condições de exploração do capital acumulado ${ }^{9}$. As principais medidas globais da política monetária e fiscal destinadas a regular os ciclos econômicos são as seguintes: a alocação de crédito, as garantias de preço, as subvenções, os empréstimos públicos aprovados em função da política conjuntural e a política de emprego.

Se a planificação global se limita a corrigir as disfunções do mercado, o Estado o substitui na tarefa de criar ou melhorar certas condições de exploração do capital acumulado. Assim, dentre outras coisas, ele

7. Cf. Idem, p. 53

8. Cf. KEANE, J. Public Life and late capitalism: Toward a socialist theory of democracy, Cambridge: Cambridge University Press, 1984, p. 80.

9. Cf. Idem, p. 83. 
reforça a competitividade nacional organizando blocos econômicos supranacionais, desenvolve o consumo público improdutivo, conduz o capital em direção a setores privados negligenciados pelo mercado, melhora a infra-estrutura material, aumenta a força produtiva do trabalho humano (programas de escolarização) e atenua as consequências materiais e sociais derivadas da apropriação privada ${ }^{10}$. Tais atividades são reações às tendências de crise dos antigos mecanismos de mercado e funcionam como estratégias de gestão da crise, através das quais o Estado responde a eventuais bloqueios no processo de acumulação ${ }^{11}$.

O Estado do capitalismo tardio se move, portanto, entre as lacunas funcionais do mercado, intervém no processo de acumulação e compensa as consequências politicamente insuportáveis deste último, terminando por afetar o princípio social de organização que repousa sobre a institucionalização de um mercado de trabalho não organizado. Como resultado, no capitalismo tardio, Estado e sociedade não podem mais ser vistos a partir da metáfora da base/superestrutura, pois as relações capitalistas de produção foram repolitizadas ${ }^{12}$.

Este ultimo processo gera um fenômeno crucial para a compreensão da teoria habermasiana sobre a crise: a necessidade crescente de legitimação do sistema político. As fraquezas funcionais do mercado e suas consequências revelam as disfunções deste mecanismo de regulação e acabam, por causa da intervenção estatal, com a ideologia burguesa da troca justa. Se o Estado não se contenta mais em garantir as condições gerais da produção e intervém nela, ele deve ser legitimado. Por isso, a repolitização das relações de produção cria uma necessidade extra de legitimação. Para isso, contudo, não é mais possível apelar para as reservas de tradição já desgastadas ao longo da expansão do capitalismo. Ademais, os valores universalistas da ideologia burguesa tornaram universais os direitos cívicos, sobretudo o direito de participar das eleições. Desta forma, a legitimidade deve ser assegurada com bases universais no quadro de uma democracia formal.

Chega-se então ao paradoxo típico do capitalismo tardio analisado por Habermas: "a transformação estrutural da esfera pública burguesa gera, para as instituições e procedimentos da democracia formal,

10. Cf. HABERMAS, J. Legitimationsprobleme im Spätkapitalismus. Frankfurt: Suhrkamp, 1973 , p. 53.

11. Cf. KEANE, J. Public Life and late capitalism, p. 85.

12. Cf. Idem, p. 83. 
condições de aplicação nas quais os cidadãos assumem - no interior de uma sociedade nela mesma política - o estatuto de cidadãos passivos com o direito de negar suas aclamações ${ }^{\prime \prime 13}$. Isto é, apesar da repolitização da sociedade e do desabrochar de valores universalistas em uma democracia (formal), os cidadãos permanecem passivos e aceitam uma formação tecnocrática da vontade política. As decisões não democráticas sobre os investimentos estatais encontram o seu complemento necessário na despolitização e no privatismo cívico dos cidadãos. A atenuação da efetiva participação política das massas, contudo, não éfortuita a despolitização é um imperativo desta configuração social, já que as prioridades das políticas estatais concernentes à apropriação privada da produção socializada devem ser retiradas da discussão pública genuína ${ }^{14}$. Sobre este ponto, Offe sublinha que o problema estrutural do Estado no capitalismo tardio reside no fato de que a lealdade das massas se torna um problema permanente, uma vez que o Estado deve pôr em prática o seu caráter de classe e, ao mesmo tempo, obscurecer este viés. Sob a pressão deste problema estrutural, as elites políticas acabam por desencorajar uma vida pública autônoma ${ }^{15}$.

Nesse contexto, a conclusão de Habermas é a de que, no caso de uma opinião pública estruturalmente despolitizada, o processo de legitimação se reduz a necessidades residuais. $\mathrm{O}$ interesse dos cidadãos se orienta pelo consumo, por lazeres e pela carreira, sua expectativa é a de obter compensações apropriadas (dinheiro, tempo livre e segurança $)^{16}$. Um programa de substitutivos é então elaborado pelo Estado social.

13. Cf. HABERMAS, J. Legitimationsprobleme im Spätkapitalismus, p. 55.

14. Cf. KEANE, J. Public Life and late capitalism, p. 89.

15. Cf. OFFE, C. The theory of capitalist state and the problem of policy formation. In: Lindberg L N, Alford R, Crouch C, O e C (eds.) Stress and Contradiction in Modern Capitalism. Lexington: Lexington Books, 1975, p. 127.

16. O privatismo dos cidadãos corresponde ao interesse em prestações do sistema administrativo nos domínios da regulação e da seguridade social, com uma participação no processo de legitimação limitada às ocasiões previstas de modo institucional (sufrágio universal, por exemplo), o que significa uma opinião pública despolitizada. De outro lado, a atitude privada na vida familiar e profissional se identifica com uma vida orientada para a família (lazeres e consumo) e para a carreira profissional (concorrência pelo status social), o que corresponde às estruturas de um sistema de emprego e de educação regulado pela concorrência entre os desempenhos individuais. Cf. HABERMAS, J. Legitimationsprobleme im Spätkapitalismus, p. 106. 


\section{Teoremas de Crises}

Depois da apresentação do diagnóstico do capitalismo tardio, falta uma análise sobre como Habermas concebe as tendências reais à emancipação. Pois, apesar dos processos de neutralização do conflito de classes e de racionalização da vida econômica, via mecanismos estatais de gestão das crises, ele não recai na tese do "mundo totalmente administrado". Pelo contrário, junto com Offe, Habermas mantém, em Problemas de Legitimação, a ideia de que as sociedades burocratizadas do capitalismo avançado são sistemas passíveis de contradições, de crises internas e de crítica ${ }^{17}$.

Apesar disso, é importante assinalar que, naquilo que diz respeito aos prognósticos de crise, Habermas assume uma postura bem mais cautelosa do que certos autores de extração marxista. Ele fala apenas de possíveis tendências de crise e afirma que o problema de saber se uma auto-transformação do capitalismo tardio é possível, é uma questão aberta $^{18}$. Sob as condições do capitalismo tardio, Habermas parece não mais contar com uma crise econômica final cujas contradições sistêmicas (p. ex., queda tendencial da taxa de lucro) conduziria imediatamente a uma crise social e política que exporia a nu o antagonismo de interesses entre as classes, gerando uma luta de classes revolucionária em escala mundial. Sua hipótese central indica que "a tendência persistente que conduz a perturbações no crescimento capitalista pode ser transformada administrativamente e progressivamente deslocada, através de um sistema político, para o sistema sócio-cultural"19. Assim, Habermas se diferencia de Marx ao não mais localizar os principais focos de crise diretamente no âmbito econômico. Ao mesmo tempo, ele se mostra disposto a investigar novos focos de crises que podem eventualmente surgir em outros âmbitos da sociedade, tais como o político e o sócio-cultural. Não à toa, o primeiro capitulo de Problemas de Legitimação é dedicado à delimitação de um adequado conceito sociológico de crise.

17. Acompanhando Offe, Habermas já inicia o livro definindo o que ele entende por "capitalismo tardio". Neste momento, ele afirma que utilizar essa expressão significa levantar a hipótese de que, mesmo num capitalismo regulado estatalmente, o desenvolvimento social se dá de modo contraditório ou provocando crises (Idem, p. 9). Ver também KEANE, J. Public Life and late capitalism, p. 95.

18. Cf. HABERMAS, J. Legitimationsprobleme im Spätkapitalismus, p. 60.

19. Cf. Idem, p. 62. 
Para Habermas, no capitalismo tardio, fortemente marcado pela regulação estatal, a economia não mais determina tudo. Uma vez que a relação entre as classes se repolitiza, a economia não assegura mais a integração social. Com isso, muda a própria lógica da crise. É, por essa razão, que Habermas afirma que uma retradução sociológica, em termos de conflitos de classe, dos problemas identificados a partir de uma análise estritamente econômica cria dificuldades quando aplicada às condições alteradas do capitalismo organizado ${ }^{20}$. Como captar então essa nova lógica? Habermas tenta pensar, inicialmente, um conceito geral de crise, a principio aplicável para todas as formas de organização social, e não mais apenas para o capitalismo liberal. Somente num segundo passo ele tentará aplicar e adaptar esse conceito geral à realidade do capitalismo tardio.

Comecemos pelo conceito geral. Grande parte do primeiro capítulo é dedicada à essa tarefa.

Segundo Habermas, um conceito adequado de crise deve ser suficientemente complexo para abarcar sua dimensão sistêmica (problemas funcionais no âmbito das forças produtivas e da capacidade de regulação administrativa) bem como a dimensão social dos atores em disputa, assim como relacioná-los corretamente entre si.

Habermas concebe os componentes dos sistemas sociais a partir de um modelo tridimensional. Assim, há essencialmente três esferas: a sócio-cultural (estruturas normativas), a política e a econômica. A primeira diz respeito ao âmbito social, e os dois últimos correspondem à dimensão propriamente sistêmica da sociedade. O desafio, segundo Habermas, é a união de ambos os paradigmas, não apenas em uma teoria social, mas também no quadro analítico de uma teoria das crises. Sua teoria dualista da sociedade pretende realizar isso, ultrapassando as fraquezas de cada paradigma considerado isoladamente. O conceito de crise em Habermas aparece justamente a partir da distinção feita entre a integração social e a integração sistêmica.

Os sistemas econômico e político-administrativo podem ser vistos como sistemas autorregulados, onde predomina a integração sistêmica ${ }_{i}$ as "crises" são aqui produzidas quando estes subsistemas se tornam disfuncionais (por exemplo, no caso de crises econômicas de superprodução e crises administrativas de ineficiência ou de regulação). Todavia, de acordo com o paradigma da integração social, os proble-

20. Cf. Idem, p. 49. 
mas de regulação sistêmica só são de fato perigosos "na medida em que o consenso que está na base das estruturas normativas é ameaçado ao ponto em que a sociedade se torna anômica. Os estados de crise se apresentam sob a forma de uma desintegração das instituições sociais. Os sistemas sociais têm eles também a sua identidade e eles podem perdê-la"21. Esta última concepção de crise diz respeito portanto diretamente ao subsistema sócio-cultural, no qual indivíduos e coletividades constituem e reproduzem sua identidade em relação a valores, normas e sistemas de sentido.

Por isso, se impõe à Habermas a tarefa de articular os conceitos de crise sistêmica e de crise vivida. Com vistas a realização dessa tarefa, Habermas propõe o seguinte conceito de crise:

os fenômenos de crise devem sua objetividade ao fato de que eles nascem de problemas de regulação deixados sem solução. As crises de identidade estão em correlação com os problemas de regulação. Os sujeitos que agem não são conscientes durante a maior parte do tempo acerca dos problemas de regulação, mas estes problemas engendram problemas derivados que produzem, estes, efeitos de forma específica na consciência destes sujeitos, de tal sorte que a integração social é posta em perigo. A questão que se põe é, entretanto, saber quando aparecem problemas de regulação que cumprem com esta condição. Um conceito de crise apropriado às ciências sociais deve, portanto, captar a correlação entre integração social e integração sistêmica ${ }^{22}$.

Ora, se a questão é a de determinar quando os problemas de regulação geram ameaças à identidade do sistema social, é preciso introduzir uma análise historicamente orientada dos sistemas sociais que determine o âmbito de tolerância ou a margem de manobra que cada tipo de sistema social suporta no nível da regulação, sem que com isso a integração social seja posta em perigo.

Neste momento, Habermas toca na questão da evolução social e recupera o conceito marxista de formação social, de acordo com o qual a formação de uma sociedade é, a cada momento, determinada por um princípio de organização fundamental que delimita um espaço abstrato no interior do qual as mudanças de estágios sociais são possíveis. Estas mudanças, quando significam evoluções nas várias dimensões do sistema social, são compreendidas como um processo de aprendizagem. Segundo Habermas, a evolução social ocorre nas três

\footnotetext{
21. Idem, p. 14

22. Idem, p. 15.
} 
dimensões sociais, isto é, no desenvolvimento das forças produtivas, no aumento de autonomia sistêmica em relação ao meio circundante e nas alterações das estruturas normativas. Contudo, a ampliação da autonomia do sistema político depende de desenvolvimentos nas duas outras dimensões que, para Habermas, podem ser reconstruídos segundo um padrão racional ${ }^{23}$. Além disso, é importante ressaltar que o desenvolvimento das forças produtivas e as mudanças nas estruturas normativas seguem padrões de desenvolvimento que são logicamente independentes um do outro ${ }^{24}$.

A concepção habermasiana da crise está vinculada aos princípios de organização e à relação entre o desenvolvimento das forças produtivas e as mudanças nas estruturas normativas. De acordo com ele, os problemas de regulação só conduzem a crises quando eles não podem ser resolvidos no interior do campo de variações possíveis que o principio de organização de uma sociedade circunscreve ${ }^{25}$. Mas, se a capacidade de regulação de uma sociedade (ou a autonomia do sistema em relação ao meio) depende do nível das forças produtivas e das estruturas normativas, a relação entre estes dois últimos âmbitos é fundamental para a deflagração da crise. Assim, embora os desenvolvimentos de ambos sejam autônomos, eles não deixam de se relacionar na efetividade histórica. Habermas afirma, por exemplo, que as estruturas normativas podem ser transformadas mediante uma dissonância cognitiva entre a ampliação do saber profano por meio do desenvolvimento das forças produtivas e a dogmática de imagens de mundo tradicionais. Isso não quer dizer que o âmbito sistêmico determine o âmbito das estruturas normativas, afinal os mecanismos que causam os impulsos de desenvolvimento nas estruturas normativas são diversos da lógica do desenvolvimento destas últimas. Por isso, não é certo que um desenvolvimento das forças produtivas conduza a mudanças normativas que correspondam exatamente às necessidades dos imperativos de regulação dos sistemas sociais. Assim, ainda que haja um entrelaçamento na dinâmica de desenvolvimento dos âmbitos sistêmico e social, não há uma determinação da lógica de desenvolvimento de um ou de outro. Isso é importante para assegurar a possibilidade

23. Para uma compreensão mais pormenorizada da racionalidade desse padrão e de como a linguagem e determinadas pretensões de validade se relacionam com a evolução social de cada subsistema, ver: Idem, p. 20-22.

24. Cf. Idem, p. 22.

25. Cf. Idem, p. 18 . 
de que o desenvolvimento do âmbito sistêmico conduza a mudanças no âmbito da integração social, que imponham restrições em relação à autonomia dos sistemas sociais com novas pretensões de legitimidade, o que será importante para a inteligibilidade da lógica da(s) crise(s) no capitalismo tardio ${ }^{26}$.

Como se vê, na teorização geral da crise elaborada por Habermas, a ênfase deixa de recair pura e simplesmente na evolução do movimento econômico, para se concentrar na inter-relação e na coerência potencialmente problemática entre os percursos evolutivos de cada subsistema. Dado que a intervenção estatal retirou da economia capitalista a sua capacidade ideológica de legitimar a dominação de classe, é precisamente esse modelo - que complexifica as relações entre integração sistêmica e integração social - que é adequado ao capitalismo tardio. Como nota Offe, nesse caso, a ideia de crise capitalista é mais ampla que a de crise econômica, pois as tendências de crise não surgem (apenas) do sistema de troca enquanto tal, mas se concentram na relação entre as três diferentes esferas sociais.

Mas se, como vimos, a repolitização das relações de produção cria uma necessidade extra de legitimação, o núcleo do argumento habermasiano vai enfatizar aquelas crises que surgem da relação entre o subsistema administrativo e o subsistema sócio-cultural. Isto é, a crise administrativa, de um lado, e as crises de legitimação e de motivação, de outro. No que se segue, veremos mais detalhadamente como Habermas trata de cada um desses tipos de crise no capitalismo tardio, bem como da relação entre eles.

\section{1 - A crise administrativa}

No capitalismo tardio, a contradição fundamental do capitalismo passa do sistema econômico para o sistema administrativo em virtude da crescente intervenção estatal e do amortecimento das perturbações engendradas pelas disfunções econômicas. Com isso, o ciclo econômico dá lugar à inflação e a uma crise crônica no setor das finanças públi$\operatorname{cas}^{27}$. Nesse contexto, o Estado tem de dar conta de duas tarefas fundamentais: ele deve incentivar a manutenção do movimento de acumulação de capital, bem como assegurar a lealdade das massas. Ora, a socia-

26. Cf. Idem, p. 25.

27. Idem, p. 88 . 
lização da produção que, como antes, é orientada por objetivos privados, comporta exigências que o aparelho de Estado não pode satisfazer porque são paradoxais ${ }^{28}$. A necessidade de ampliar a capacidade de planificação do Estado a fim de realizar o interesse geral dos capitalistas (a manutenção do sistema) se choca com a necessidade de manter um espaço de liberdade de investimento aos capitalistas individuais. Assim, a planificação estatal entra num movimento oscilatório entre uma ampliação da sua autonomia em face dos seus destinatários e uma submissão a interesses particulares. Donde a impossibilidade estrutural do Estado capitalista se tornar um "capitalista coletivo ideal"29.

No entanto, apesar da importância da crise administrativa, Habermas considera as crises do âmbito sócio-cultural como as mais relevantes. Para ele, o tipo de conflito social evidenciado pelos problemas administrativos nos remetem, em última análise, a problemas de lealdade das massas, isto é, para uma crise nos mecanismos de legitimação e motivação. A tese de Habermas é que os problemas de planificação não são produzidos prioritariamente por déficits de racionalidade administrativa, mas antes por um déficit de motivação:

Dito grosseiramente, o capitalismo tardio não sofre necessariamente danos quando o instrumento de regulação que representa os estímulos externos cessa de ser eficaz em certos domínios do comportamento onde ele funcionou até agora. Em todo caso, ele encontra dificuldades quando o sistema administrativo não pode mais assumir tarefas ou funções de planificação de importância vital, pois o domínio de setores de comportamento importantes para esta planificação lhe escapa de uma maneira geral, quaisquer que sejam os meios empregados. Mas pode-se fundar este prognóstico não sobre uma perda de racionalidade da administração, mas, de toda forma, sobre um enfraquecimento de certas motivações necessárias ao sistema ${ }^{30}$.

Nota-se, portanto, que ele não trabalha mais simplesmente com a ideia de uma "catástrofe sistêmica", em que uma crise fiscal ou administrativa viria substituir a crise econômica. Habermas aposta muito mais na disfuncionalidade crescente entre a economia e a administração, de um lado, e a cultura e a personalidade, de outro. Para ele, os questionamentos e conflitos sociais não dependem do colapso da

\footnotetext{
28. Idem, p. 89.

29. Cf. KEANE, J. Public Life and late capitalism, p. 96.

30. HABERMAS, J. Legitimationsprobleme im Spätkapitalismus, p. 96.
} 
economia ou do Estado planificador para eclodirem. De acordo com o seu conceito geral de crise, os problemas de regulação têm a sua importância e dão objetividade às crises, no entanto, as crises só são efetivamente deflagradas quando estes problemas sistêmicos suscitam efeitos específicos na consciência dos sujeitos, na medida em que a integração social é posta em perigo. Passemos então para uma análise mais detida das crises relativas ao âmbito sócio-cultural.

\section{2 - A crise de legitimação}

Apesar da ruptura do "véu" do fetichismo da mercadoria e da repolitização das relações de produção, o Estado teve de manter uma parte de inconsciência a fim de que suas funções de planificação não lhe imponham responsabilidades que ele não poderia aceitar sem esvaziar seus caixas ${ }^{31}$. Assim, ainda que as tendências de crise fiscal persistam, quando se trata de gastar de modo racional os recursos, para Habermas, a atividade do Estado encontra limites efetivos; mas estes dependem das legitimações disponíveis ${ }^{32}$. Agora, passa a ser preciso justificar a cobrança fiscal, diferente segundo as camadas sociais, e a utilização particularista dos recursos, que uma política de afastamento das crises utiliza e esgota. Disso resulta a necessidade funcional de tornar o sistema administrativo o mais independente possível do sistema de legitimação, o que explica a necessidade de manter o privatismo dos cidadãos enquanto um recurso de motivação fundamental da ação capitalista. A personalização de problemas concretos, o emprego simbólico de procedimentos de consulta, de julgamentos de especialistas, de fórmulas de encantamento jurídicas, a publicidade, etc., representam estratégias para a produção de uma obediência difusa. Mas Habermas destaca que "não há produção administrativa de sentido"33, o que quer dizer que a sociedade capitalista permanece dependente de condições culturais que ela mesma não pode produzir. A produção comercial e a planificação administrativa de símbolos esgotam a força normativa das tradições culturais e os meios pelos quais se adquire a legitimação são progressivamente consumidos.

As tradições culturais têm suas próprias condições de reprodução e só continuam vivas na medida em que se desenvolvem de forma

\footnotetext{
31. Cf. Idem, p. 98.

32. Cf. Idem, ibidem.

33. Cf. Idem, p. 100.
} 
espontânea ou pseudo-natural, garantindo a continuidade de uma história por intermédio da qual os indivíduos e os grupos podem se identificar consigo mesmos e entre si. Ora, segundo Habermas, "a expansão da atividade estatal tem por consequência indireta um aumento desmedido da necessidade de legitimação", uma vez que "evidências culturais que eram até aqui condições marginais de aplicação do sistema político entram no domínio da planificação da administração" ${ }^{\prime \prime 4}$. Desde então tradições, que não faziam parte dos programas públicos e das discussões de ordem prática, são tematizadas e questionadas. A planificação da educação, a planificação urbana, aquela do sistema de saúde e da família exigem uma justificação universal (já que o Estado representa - em tese - todos os cidadãos) para esferas caracterizadas precisamente por seu poder de auto-justificação. Isto gera a tomada de consciência do caráter contingente não apenas dos conteúdos da tradição, mas também das técnicas de transmissão, isto é, de socialização ${ }^{35}$. Assim, em todos os planos, a planificação administrativa implica involuntariamente uma perturbação e uma publicidade que enfraquecem o potencial de justificação de tradições que perderam seu caráter espontâneo ${ }^{36}$. Segundo Habermas, "uma vez que seu caráter indiscutível foi destruído, as pretensões de validade só podem ser estabilizadas por discussões. A desestabilização das evidências culturais favorece, portanto, a politização de domínios da vida cotidiana que podiam até aqui ser confiados à vida privada. Mas isto comporta um perigo para o privatismo dos cidadãos, assegurado de maneira informal pelas estruturas da opinião publica" ${ }^{\prime \prime 2}$. Habermas identifica os signos desta evolução

34. Idem, p. 101.

35. Enquanto a administação escolar de antes só tinha que decodificar um Canon que se tinha firmado de forma espontânea, a planificação do currículo, por exemplo, repousa sobre a premissa de que os modelos de tradição poderiam ser diferentes. Cf. Idem p. 102.

36. Ou, como atesta Thomas McCarthy: "a atividade expandida do Estado produz um aumento na necessidade de legitimação, por justificação da intervenção do governo em novas áreas da vida. Ao mesmo tempo, o próprio processo de submeter setores da vida social ao planejamento administrativo produz o efeito colateral não intencional de minar legitimações tradicionais (...) E esse desenvolvimento coloca em risco o privatismo civil, essencial para a esfera pública despolitizada" (MCCARTHY, T. The Critical Theory of Jürgen Habermas, pp. 369-370).

37. HABERMAS, J. Legitimationsprobleme im Spätkapitalismus, p. 102. Grifo nosso. 
nos esforços de participação e na aparição de modelos diferentes, em particular nos domínios culturais como a escola e a universidade, a imprensa, a Igreja, o teatro, as editoras, etc.

No entanto, o argumento habermasiano ainda está incompleto. Se a tese de Habermas, segundo a qual uma esfera sócio-cultural não pode ser arbitrariamente tornada funcional, puder explicar um agravamento das necessidades de legitimação que conduziria a uma crise, esta explicação "deve repousar sobre uma crise de motivação, isto é, sobre uma inadequação entre, de uma parte, a necessidade de motivos [de ação] que o Estado, o sistema educativo e o sistema de emprego fazem valer e, de outra parte, a oferta de motivação, as motivações ofertadas pelo sistema sócio-cultural" ${ }^{\prime 38}$.

\section{III.3 - A crise de motivação}

Os argumentos que depõem a favor da existência de uma crise de motivação dizem respeito a mudanças na própria esfera sócio-cultural, que acabam por ameaçar a complementaridade que existe entre as exigências do aparato estatal e as expectativas de legitimação e as necessidades dos membros da sociedade ${ }^{39}$. Como vimos, a motivação mais importante para a manutenção dos sistemas de ação social do capitalismo tardio consiste em uma atitude privada na vida pública dos cidadãos, bem como em sua vida profissional e familiar. A tese de Habermas é a de que estes modelos de motivação são destruídos em razão de uma dinâmica interna às sociedades do capitalismo tardio. Para defender essa tese, ele deve mostrar não só o esgotamento das tradições que sustentam tais atitudes, mas também que o capitalismo não pode mobilizar novos recursos de motivação a fim de substituir funcionalmente os primeiros.

Naquilo que concerne às tradições culturais ligadas aos modelos de motivação da atitude privada, Habermas afirma que se trata de uma mistura entre elementos tradicionais burgueses e pré-capitalistas. Seu pressuposto é o de que "as sociedades capitalistas foram sempre dependentes de condições marginais culturais que elas não podiam engendrar a partir delas mesmas: elas parasitam as reservas de tradições ${ }^{\prime \prime 4}$. Para defender sua tese, Habermas tenta então mostrar que estas duas

\footnotetext{
38. Cf. Idem, p. 105.

39. Cf. MCCARTHY, T. The Critical Theory of J. Habermas, p. 371.

40. HABERMAS, J. Legitimationsprobleme im Spätkapitalismus, p. 107.
} 
fontes culturais, as reservas de tradição pré-burguesas e as burguesas, estão esgotadas. As imagens de mundo tradicionalistas foram enfraquecidas continuamente no curso da evolução do capitalismo, já que elas eram inconciliáveis, sobretudo, com a extensão dos domínios onde predomina a ação racional com respeito a fins. Mas, mesmo os elementos das ideologias burguesas que favorecem as orientações privatistas perdem o seu lugar em razão das transformações sociais. A ideologia da performance é posta em questão pelo descompasso entre a formação escolar e o sucesso profissional. $\mathrm{O}$ individualismo possessivo desmorona pelo aumento da parte dos bens de uso coletivos (os transportes, os lazeres, a saúde, a educação, etc.) entre os bens de consumo ${ }^{41}$. Enfim, a orientação para valores de troca é minada em consequência do enfraquecimento da socialização do mercado ${ }^{42}$.

De acordo com o diagnóstico habermasiano, a erosão das reservas de tradição pré-capitalistas e capitalistas engendra estruturas normativas "residuais" que não são adequadas à reprodução do privatismo na vida cívica e na vida profissional-familiar. Temos aqui um exemplo claro daquilo que Habermas estabeleceu como um possível efeito da interação entre a evolução sistêmica e a evolução do âmbito sócio-cultural: na medida em que a lógica de desenvolvimento deste último é independente da primeira, temos que a transformação da esfera sócio-cultural induzida justamente pelo desenvolvimento sistêmico faz com que ela se torne disfuncional em relação aos imperativos da economia e da administração, ameaçando assim a coerência de conjunto do capitalismo tardio. Há, portanto, uma espécie de conflito entre os valores propostos pela esfera sócio-cultural e os valores necessários para a manutenção dos sistemas político e econômico estruturados em classes. Entre os elementos tornados dominantes na tradição cultural, é necessário mencionar o cientificismo na dimensão cognitiva ou teórica, a arte pós-aurática na dimensão estética e, sobretudo, a moral universalista na dimensão prático-moral.

O advento de uma ética comunicativa, segundo a qual apenas interesses universalizáveis são passíveis de serem aceitos numa discussão coletiva livre de constrangimentos, é certamente o mais importante entre os elementos culturais derivados das ideologias burguesas que produzem um efeito de bloqueio no desenvolvimento dos sistemas

41. Cf. Idem, p. 116.
42. Cf. Idem, p. 117. 
econômico e político. Este último aspecto é aquele que explicita mais nitidamente este efeito, já que o capitalismo tardio (tal como outras formas de organização social baseadas numa estrutura de classes) precisa estabilizar a contradição fundamental de uma produção socializada apropriada segundo interesses particulares (não-universalizáveis). Por isso, a eventual propagação da ética comunicativa universal nos processos de socialização é um elemento fundamental para a deflagração de uma crise de motivação no seio do capitalismo tardio.

Habermas afirma que existem duas possíveis saídas para a crise de legitimação/motivação: "Ou bem as estruturas de classes latentes do capitalismo tardio são transformadas, ou bem a exigência de legitimação à qual é submetido o sistema administrativo é suprimida. Isto só poderia se realizar se a integração da natureza interna fosse reorganizada de maneira geral segundo um outro modo de socialização, isto é, se ela fosse descolada das normas que reclamam uma justificação"43. É bom insistir, porém, que, se ele ainda fala de uma transformação da estrutura de classes, ele não o faz a partir do paradigma da revolução ou do "essencialismo" da luta de classes. Apesar de não ser tão claro em relação a uma estratégia política mais concreta, tudo indica que tratar-se-ia antes de buscar uma saída democrática para tais impasses, o que só seria possível mediante uma politização das massas e o reavivamento da esfera pública. Não se trata, portanto, de se limitar ao proletariado como pólo de luta contra a dominação de classe, pois outros movimentos, como o estudantil, mereceram a atenção de Habermas nesse período. No entanto, a esta altura, ele não tem propriamente uma "teoria da democracia", mas apenas uma "teoria da democratização" vinculada a uma teoria da crise de legitimação/ motivação.

Habermas deve ainda mostrar como o sistema cultural socializa tais estruturas. Sua tese é a de que já podemos observar na fase adolescente os primeiros elementos desta socialização "não-funcional"; o principal sintoma se encontra no momento da saída da "crise da adolescência". Uma saída não-convencional para a crise é marcada por uma atitude reflexiva que o adolescente adota em relação aos modelos de interpretação socialmente oferecidos, o que lhe permite elaborar a

43. Idem, p. 130 . 
definição de sua identidade opondo-se a estas interpretações culturais ${ }^{44}$. Como efeitos concretos dessa crise da adolescência, consta o movimento estudantil, as revoltas nos colégios e dos jovens operários ${ }^{45}$.

Como se vê, o conceito de crise em Habermas não possui apenas a função sociológica de vincular os âmbitos da integração social e da integração sistêmica, ele atua também como um conceito crítico. Pelo menos neste livro, ele vincula a possibilidade de questionamento da despolitização das massas e do bloqueio estrutural da formação democrática da vontade política às crises internas que podem surgir no decorrer do desenvolvimento do capitalismo tardio. De fato, não se trata mais de apostar simplesmente no colapso do sistema econômico ou político, mas antes no surgimento de obstáculos à reprodução sistêmica suscitados por ela mesma no decorrer de sua atividade. Se as crises de legitimação e de motivação, a despeito da relativa independência da lógica evolutiva da esfera sócio-cultural, são suscitadas involuntariamente pela dinâmica da intervenção estatal, isso significa que o capitalismo tardio encontra limites internos à sua expansão ${ }^{46}-$ intui-

44. Entre os indicadores de apoio, ele menciona o alongamento do período de formação e, em razão de uma moratória psicossocial, a elevação das aptidões cognitivas; o desenvolvimento de estruturas familiares igualitárias; a relativização dos interditos sexuais proporcionada pelos produtos farmacêuticos e, por isso, uma socialização com menos angústia e com mais margem de jogo para as experiências da adolescência. Cf. Idem, p. 126.

45. Cf. Idem, p. 128.

46. Parece que Hartmann e Honneth também partilham dessa interpretação em relação ao modelo de 1973: "Quando Jürgen Habermas formulou esta frase em seu estudo sobre os 'problemas de legitimação do capitalismo tardio', no início da década de 1970, isso estava ligado ao diagnóstico de que os recursos motivacionais tradicionais da ação capitalista (privatismo civil e familiar-profissional) seriam corroídos pelas conquistas do Estado de bem-estar, de modo que a contradição entre capital e trabalho, que continua a permear as sociedades capitalistas avançadas, iria ser privada de seu véu legitimante à luz de uma moral crítica orientada por critérios cada vez mais universalistas. Segundo esta interpretação, a sociedade do capitalismo tardio é contraditória tanto em termos de antagonismos de classe 'latentes', quanto no sentido da lógica do desenvolvimento que leva as tendências 'destradicionalizantes' (detraditionalizing) do capitalismo de Estado de bem-estar a expor auto-destrutivamente as desigualdades e injustiças típicas desta fase do capitalismo" (HARTMANN, M.; HONNETH, A. Paradoxes of Capitalism. In: Constellations, Volume 13, N. 1. Oxford: Blackwell, 2006, p. 46). 
ção que será aparentemente descartada por nosso autor quando da elaboração de sua obra-prima ${ }^{47}$. Desse modo, as crises desempenham aqui um papel importante no delineamento dos prognósticos de emancipação. Da mesma forma, a crise contribui para a crítica do capitalismo na medida em que explicita as contradições internas do sistema. A função da crítica não é terapêutica, ela se apresenta, antes, como um diagnóstico da crise que permite o prognóstico de uma tendência à transformação social.

\section{Problemas de Legitimação: uma visão retrospectiva}

O texto de 1973 é passível de muitos questionamentos importantes. Não muito tempo depois que o livro foi publicado, Thomas McCarthy já questionava alguns pontos importantes do prognóstico de uma crise de motivação, ao afirmar que os estudos de psicologia sobre os quais Habermas se baseia eram incipientes e inconclusos. Assim, seria muito cedo para prever que haveria um crescente nível de protesto, no lugar de uma acomodação mais hedonística em relação às exigêncuas do sistema politico-econômico ${ }^{48}$.

Se considerarmos o momento presente, a crítica de McCarthy é reforçada pela dinâmica atual do capitalismo neoliberal. Martin Hartmann e Axel Honneth também realizaram uma importante crítica ao modelo de Problemas de Legitimação que vai nesta direção. Em um artigo sobre os paradoxos do capitalismo contemporâneo, eles mostram que Habermas se enganou em relação ao fato de que os recursos motivacionais do capitalismo teriam se esgotado. Segundo eles, o capitalismo contemporâneo foi bem-sucedido na mobilização de novos

47. Uma possível explicação para esse posterior abandono da noção de crise enquanto limite interno à expansão do sistema pode ser encontrada no fato de que Habermas passou a considerar que a formação democrática da vontade política seria compatível com uma certa forma de capitalismo tardio e, portanto, com o seu caráter de classe. Nesse caso, tal como a economia, o Estado social deveria ser controlado e tornado "reflexivo". Assim, a partir dos anos 80 , a causa estrutural da despolitização passa a se localizar não tanto mais no caráter classista do Estado social, mas nos "excessos" de sua expansão desenfreada, que atingiu domínios do mundo da vida e gerou processos patológicos de reificação e de juridificação. Para um desenvolvimento mais detalhado desse argumento, ver DA HORA PEREIRA, L. A noção de capitalismo tardio na obra de Jürgen Habermas, segunda parte. 
recursos motivacionais ${ }^{49}$. Uma das principais fontes destes dois autores são os trabalhos dos sociólogos franceses Luc Boltanski e Ève Chiapello, segundo os quais o neoliberalismo deve parte de sua força integrativa ao apelo a valores tidos como emancipatórios na época anterior, tais como responsabilidade, flexibilidade, autonomia e capacidade de estabelecer redes de contatos e "amigos"

Além disso, olhando retrospectivamente, subsiste uma lacuna de fundo na análise habermasiana. Na medida em que tomou por objeto um capitalismo de tipo europeu e estatalmente regulado, Habermas subestimou consideravelmente a importância da dinâmica propriamente econômica do capitalismo, bem como das suas potenciais crises, inclusive as crises financeiras. Mesmo com todos esses problemas, o tipo de empreendimento que Habermas realiza nesta obra ainda parece poder oferecer elementos de inspiração importantes para futuros diagnósticos.

Apesar da ideologia neoliberal do não intervencionismo estatal, pensar que a economia de mercado funcionaria hoje em dia sem a regulação do Estado é uma ilusão. A evolução das políticas macroeconômicas desde a Grande Crise de 1929 se fez presente em 2008, quando, "com o sistema financeiro global prestes a se desintegrar, os Estados-nação buscaram restituir a confiança econômica socializando os créditos podres emitidos como forma de compensar a consolidação fiscal $^{1 / 51}$. Neste contexto, a atualidade de uma crise administrativa, dessa vez diretamente provocada por uma crise financeira, pode talvez se revelar na questão da consolidação fiscal, cujo exemplo mais notório se deu no episódio da crise da dívida soberana na Europa em 2011.

Tal como Habermas havia diagnosticado em 1973, o Estado intervencionista se vê diante de duas tarefas fundamentais: de um lado, ele deve incentivar a manutenção do movimento de acumulação de capital e, de outro, tem de assegurar a lealdade das massas. Para tanto, ele precisa manter um certo grau de autonomia em face dos interesses dos cidadãos, do contrário não poderia tomar decisões a favor dos interesses dos capitalistas. O dado novo é que agora a pressão a favor dos interesses destes últimos é ainda maior, pois trata-se de instituições financeiras globais, cujo poder de barganha é muito maior. é, nesse sentido, que Streeck pode falar atualmente, tal como Habermas falara em 1973, de uma tensão entre capitalismo e democracia:

49. HARTMANN, M.; HONNETH, A. Paradoxes of Capitalism, p. 46.

50. Idem, p. 45

51. STREECK, W. As crises do capitalismo democrático, p. 49. 
contudo, na atual crise, a democracia está tanto em risco quanto a economia, se não mais. Não só a "integração sistêmica" das sociedades contemporâneas — ou seja, o funcionamento eficaz de suas economias capitalistas — se precarizou, mas também sua "integração social". Com o advento de uma nova fase de austeridade, a capacidade dos Estados-nação de fazer a mediação entre os direitos dos cidadãos e os requisitos de acumulação de capital foi severamente afetada. Governos de toda parte enfrentam resistência mais forte a aumentos de impostos, particularmente em países altamente endividados, nos quais será preciso gastar dinheiro público novo por muitos anos para pagar bens consumidos há muito tempo. Além disso, com a interdependência global cada vez mais estreita, já não é possível ter a pretensão de que as tensões entre economia e sociedade, entre capitalismo e democracia, podem ser geridas no interior das comunidades políticas nacionais ${ }^{52}$.

O mais difícil hoje parece ser vislumbrar uma possível crise de legitimação ou de motivação, mas esta tensão entre capitalismo e democracia pode contribuir para isso. Como observa Streeck:

como lemos quase todo dia nos jornais,"os mercados" passaram a ditar por vias sem precedentes o que Estados supostamente soberanos e democráticos ainda podem fazer por seus cidadãos e o que devem lhes recusar (...) Desse modo, os cidadãos cada vez mais percebem seus governos não como seus agentes, mas de outros Estados ou de organizações internacionais tais como o FMI ou a União Europeia, incomensuravelmente mais isolados da pressão eleitoral do que era o tradicional Estado-nação (...) Entretanto, pleitos em que os eleitores não tenham nenhuma opção efetiva poderão ser percebidos como inautênticos, o que talvez cause toda sorte de desarranjos políticos, da diminuição do comparecimento às urnas e a ascensão de partidos populistas aos distúrbios nas ruas ${ }^{53}$.

Um outro elemento de possível desestabilização do sistema legitimatório do capitalismo talvez seja - como Habermas já havia previsto em 1973 - o abalo da ideologia da performance, segundo a qual as gratificações sociais devem ser distribuídas em função dos desempenhos individuais. No entanto, no atual contexto, os motivos de tal abalo estariam muito mais relacionados ao aumento brutal, nos

\footnotetext{
52. Idem, p. 54.

53. Idem, pp. 54-5.
} 
últimos vinte anos, dos níveis de desigualdade em países desenvolvidos, sobretudo nos $\mathrm{EUA}^{54}$, onde aliás tal ideologia é bem presente no imaginário da população. Se tal tendência se mantiver - o que por si só poderia significar uma crise social - lemas como o da "igualdade de oportunidades" ou do self-made man podem perder de vez sua eficácia prática.

Se, após a crise do Estado de Bem-estar europeu e a ascensão e crise do neoliberalismo, estivermos corretos em apontar para a volta da crítica do capitalismo ao centro da teoria crítica, a grande questão que se coloca é a de saber como e em nome de que(m) criticar o capitalismo hoje. Num capitalismo cada vez mais complexo, sujeito a crises multidimensionais, o empreendimento de Habermas em Problemas de Legitimação pode nos servir de grande inspiração nesse projeto. Motivo pelo qual ele merece ser revisitado e, em alguma medida, reatualizado.

\section{Referências Bibliográficas:}

ALVAREDO F.; PIKETTY T. The Dynamics of Income Concentration over the Twentieth Century. The Case of Advanced Economies. In: Lopez-Calva, L. \& Lustig, N. (orgs.) Markets, the State and the Dynamics of Inequality. Washington: Brookings Institution Press, 2009.

BENHABIB, S. Critique, Norm and Utopia. New York: Columbia University Press, 1986.

DA HORA PEREIRA, L. A noção de capitalismo tardio na obra de Jürgen Habermas: em torno da tensão entre capitalismo e democracia. Campinas, 232p.

Dissertação de mestrado em filosofia. UNICAMP, 2012.

DUMENIL, G.; LEVY, D. The Crisis of Neoliberalism. Cambridge, Massachussetts, London, England: Harvard University Press, 2011.

FRASER, N. Marketization, Social Protection, Emancipation: Toward a Neo-Polanyian Conception of Capitalist Crisis. Disponível em http://f.hypotheses.org/wp-content/blogs.dir/203/files/2012/02/ Texte-Nancy-Fraser-anglais.doc. Acesso em 07/2013.

54. Os trabalhos estatísticos do economista francês T. Piketty são importantes nesse sentido. Ver por exemplo ALVAREDO F., PIKETTY T. The Dynamics of Income Concentration over the Twentieth Century. The Case of Advanced Economies. In: Lopez-Calva, L. \& Lustig, N. (orgs.) Markets, the State and the Dynamics of Inequality (orgs.). Washington: Brookings Institution Press, 2009, p. 43. 
HABERMAS, J. Student und Politik: Eine soziologische Untersuchung zum politischen Bewusstsein Frankfurter Studenten. Neuwied: Hermann Luchterhand Verlag, 1961. . Technik und Wissenschaft als "Ideologie". Frankfurt: Suhrkamp, 1968. Legitimationsprobleme im Spätkapitalismus. Frankfurt: Suhrkamp, 1973.

Theorie des kommunikativen Handelns. Frankfurt am Main: Suhrkamp, 1981.

HARTMANN, M.; HONNETH, A. Paradoxes of Capitalism. In: Constellations, vol. 13, n. 1. Oxford: Blackwell, 2006.

KEANE, J. Public Life and late capitalism: Toward a socialist theory of democracy, Cambridge: Cambridge University Press, 1984.

MACCARTHY, T. The Critical Theory of Jürgen Habermas, Cambridge : MIT Press, 1981.

OFFE, C. The theory of capitalist state and the problem of policy formation. In: Lindberg L. N. (ed.) Stress and Contradiction in Modern Capitalism. Lexington: Lexington Books, 1975.

Crises of crisis management. In: OFFE, C. Contradictions of the Welfare State. Cambridge: MIT Press, 1984.

STREECK, W. As crises do capitalismo democrático. In: Novos estudos CEBRAP, São Paulo, n. 92, Mar. 2012. 